\title{
Financial strain and birth weight: The mediating role of psychological distress
}

\author{
Amanda M. Mitchell, $\mathbf{P h D}^{1,2}$ and Lisa M. Christian, $\mathbf{P h D}^{1,2,3,4}$ \\ 1Department of Psychiatry \& Behavioral Health, The Ohio State University Wexner Medical \\ Center, Columbus, $\mathrm{OH}$ \\ ${ }^{2}$ Institute for Behavioral Medicine Research, The Ohio State University Wexner Medical Center, \\ Columbus, $\mathrm{OH}$ \\ ${ }^{3}$ Department of Psychology, The Ohio State University, The Ohio State University, Columbus, $\mathrm{OH}$ \\ ${ }^{4}$ Department of Obstetrics and Gynecology, The Ohio State University Wexner Medical Center, \\ Columbus, $\mathrm{OH}$
}

\begin{abstract}
Purpose-The effects of financial strain during pregnancy have received limited attention. In addition, data examining the pathways by which SES indicators contribute to birth weight are lacking. The objective of the current study was to examine the potential pathway of psychological distress in the relationship between financial strain and birth weight.
\end{abstract}

Methods-Participants consisted of 138 pregnant women who completed measures assessing financial strain, depressive symptoms, pregnancy-specific distress, perceived stress, and general anxiety during pregnancy (mean gestational age $=18.5, \mathrm{SD}=7.2$ ). Birth outcome data were obtained via medical record review. Simple and parallel mediation models were conducted using PROCESS.

Results-Simple mediation models showed that depressive symptoms (95\% CI: -24.65, -0.90) and pregnancy-specific distress (95\% CI: $-37.31,-5.91$ ), but not perceived stress (95\% CI: $-31.17,4.69)$ or anxiety $(95 \%$ CI: $-25.84,5.57)$, served as mediators in the relationship between financial strain and birth weight. When depressive symptoms and pregnancy-specific distress were included in the same mediation model, only pregnancy-specific distress remained significant.

Conclusions-Financial strain was positively associated with all facets of psychological distress and negatively associated with birth weight during pregnancy. The current study demonstrated the mechanistic role of pregnancy-specific distress in the link between financial strain and birth weight in a racially diverse sample. Interventions targeting pregnancy-specific distress may mitigate the effects of financial strain on birth weight. Studies examining whether pregnancy-

Address correspondence and reprint requests to Lisa M. Christian, $\mathrm{PhD}$, Institute for Behavioral Medicine Research, 460 Medical Center Drive, Room 112, The Ohio State University Wexner Medical Center, Columbus, Ohio 43210. Lisa.Christian@ osumc.edu Phone: 614-293-0936 Fax: 614-293-4200.

Conflicts of Interest The authors report no potential conflicts of interest.

Financial Disclosures: This study was supported by NINR (R01NR013661, LMC). The content is solely the responsibility of the authors and does not necessarily represent the official views of the National Institutes of Health. 
specific distress accounts for the relationship between other types of stressor exposures and birth weight would be informative.

\section{Keywords}

financial strain; pregnancy-specific distress; depressive symptoms; birth weight; pregnancy; mediation

\section{Introduction}

Low birth weight is associated with serious health implications and affects $8.1 \%$ of births in the U.S. (Hamilton et al. 2013; Mattison et al. 2001). One key contributor to the delivery of low birth weight babies is socioeconomic status (SES). Of note, a systematic review with U.S. and international samples found that 93 of 106 studies reported a significant association between various SES measures (e.g., income, employment) and low birth weight, preterm birth, or small for gestational age; adverse birth outcomes were most prevalent in women with low SES (Blumenshine et al. 2010). Thus, evidence suggests that SES is important to consider in this clinically-relevant outcome.

Financial conditions (e.g., income) are commonly associated with financial pressure or strain (Conger et al. 1994). Financial strain is considered a stressor exposure with significant mental and physical health effects. For example, studies have shown that financial strain contributes to adverse health outcomes in women, such as increased oxidative stress levels, greater malnutrition risk, lower self-rated health, and recurrent coronary events (Georgiades et al. 2009; Palta et al. 2015; Samuel et al. 2012; Shippee et al. 2012). However, data examining the effects of financial strain during pregnancy are limited. These data may be especially important given the relationship between other SES measures (e.g., income) and adverse birth outcomes.

The pathways linking SES indicators to physical health are not well-delineated (Matthews and Gallo 2011). Conceptually, psychological distress has been posited to play a mediating role in the relationship between stressor exposures (e.g., low SES) and birth outcomes (Dunkel Schetter and Lobel 2010; Dunkel Schetter and Tanner 2012); this may be a promising link between financial strain and birth weight. In particular, financial strain may contribute to increased subjective psychological distress which in turn negatively affects birth weight.

In terms of general psychological distress, emerging research demonstrates a relationship between financial strain and antenatal as well as postpartum depressive symptoms (Dailey and Humphreys 2011; Grote and Bledsoe 2007; Husain et al. 2012). Moreover, depressive symptoms have been linked with birth weight, with stronger effects found in women with low SES (Hoffman and Hatch 2000; Paarlberg et al. 1999; Steer et al. 1992; ZimmerGembeck and Helfand 1996). In addition, perceived stress and general anxiety are other facets of general distress that may serve as mediators. Data examining the relationship between financial strain and pregnancy-specific distress are lacking; however, this contextually-specific anxiety has been shown to play a unique role in contributing to birth outcomes (Lobel et al. 2008). These distinct facets of distress show varying strength in their 
relation with birth weight (Dunkel Schetter and Lobel 2010); thus, simple and parallel examinations of their potential mediating roles are warranted.

To address gaps within the literature, the current study examined the mediating roles of depressive symptoms, pregnancy-specific distress, perceived stress, and general anxiety in the link between financial strain and birth weight in a racially diverse sample of 138 pregnant women.

\section{Materials and Methods}

\section{Study Design}

This study included 146 pregnant women who were recruited largely from faculty, staff, and students at the Ohio State University (OSU) and OSU Wexner Medical Center (OSUWMC). Women were also recruited from the OSUWMC Prenatal Clinic and surrounding community of Columbus, Ohio. Data collection occurred from October 2013 to September 2015. The broader study consisted of two visits (baseline and 30 days later) and three blood draws (baseline, 30 days later, and delivery) examining the immunogenicity of pregnant women after receiving the influenza vaccine. Secondary analyses in the current examination utilize psychosocial data from baseline (prior to vaccination) and birth outcomes obtained via medical record review.

\section{Participants}

Exclusion criteria included multi-fetal gestation, diagnosed fetal anomaly, chronic conditions (e.g., cancer, systemic lupus erythematosus) or use of medications (e.g., progesterone) with implications for immune function, illicit drug use other than marijuana, and consumption of $>2$ alcoholic beverages per week per self-report or medical record at time of enrollment. Women were also excluded if they were beyond 30 weeks gestation, reported weight and height consistent with a pre-pregnancy body mass index (BMI) $>50$, or did not intend to deliver at OSUWMC. Women reporting acute illness, such as cold- or flulike symptoms, or antibiotic use within ten days of a study visit were rescheduled. Five women were excluded from the current analyses because their medical records were unavailable. Written informed consent and HIPAA authorizations were obtained from all participants and each received modest compensation. The study was approved by the OSU Biomedical Institutional Review Board.

\section{Demographics and Birth Outcomes}

Age, race, marital status, education level, annual household income, employment status of participant, number of prior births (parity), and current smoking status (yes/no to current use) were collected by self-report. Gestational age at delivery and birth weight were obtained via medical record review.

\section{Financial Strain}

This index is comprised of three items which assess financial strain: "How difficult is it for you to live on your total household income right now?", "In the next two months, how likely is it that you and your family will experience actual hardships, such as inadequate housing, 
food, or medical attention?", and "How likely is it that you and your family will have to reduce your standard of living to the bare necessities in life?" (Kessler et al. 1988; Vinokur and Caplan 1987). Participants responded to items on a 5-point scale and items were summed to calculate a total score. Cronbach's alpha for this measure in this sample was .83, which is consistent with non-pregnant samples (Price et al. 2002; Vinokur et al. 1996). This index has been used to assess financial strain in prior prenatal samples (Wright et al. 2010).

\section{Psychological Distress}

The Center for Epidemiologic Studies Depression Scale (CES-D) is a well-validated 20item measure of cognitive emotional, and somatic symptoms of depression (Radloff 1977). The CES-D is predictive of perinatal health and birth outcomes (Christian et al. 2009; Christian et al. 2010; Hoffman and Hatch 2000). The Revised Prenatal Distress Questionnaire (NUPDQ) is a 17-item measure of maternal stress associated with pregnancy, which has been shown to predict birth outcomes (Lobel et al. 2008; Yali and Lobel 1999). The 10-item Perceived Stress Scale (PSS) assesses a construct independent of depressive symptomatology and has been associated with birth outcomes in perinatal populations (Cohen et al. 1983; Zambrana et al. 1999). The State-Trait Anxiety Inventory (STAI) measures general anxiety and has shown strong criterion, discriminant, and predictive validity in perinatal populations (Meades and Ayers 2011). The state portion of this measure was used in the current study.

\section{Statistical Analyses}

All analyses were conducted in SPSS 22.0. Outliers ( $n=3)$, as defined by \pm 3 standard deviations from the mean, were removed, resulting in a final analytic sample of 138 . Descriptive statistics were calculated for all women. Partial correlations were conducted to examine the relationship between financial strain and birth weight. Bivariate correlations were used to assess the relationships among psychological distress variables. To examine whether depressive symptoms, pregnancy-specific distress, perceived stress, and/or general anxiety served as mediators in relationship between financial strain and birth weight, the widely used approach developed by Preacher and Hayes was employed (Preacher and Hayes 2008). In adhering to this approach, PROCESS macros were used to estimate indirect effects and bootstrap confidence intervals were examined to determine statistical significance (Hayes 2013). Indirect effects, as compared to direct effects, were examined because in cases characterized by competitive mediation (i.e., indirect effect has significant opposing signs), a direct effect may not be significant when a mediation is present (28). All mediation models were adjusted for the following covariates: annual household income, employment status, education level, race, smoking status, and gestational age at delivery.

\section{Results}

\section{Sample characteristics}

Demographics, psychological characteristics, and birth weight are summarized in Table 1. Women were between 5-31 weeks gestation at the time of assessment (mean=18.4, $\mathrm{SD}=7.2$ ). The average age was 29.3 ( $\mathrm{SD}=4.9$, range: $19-42), 61 \%(n=84)$ were white, $61 \%$ $(n=84)$ were married, and $59 \%$ ( $n=82)$ reported having some type of college degree. 


\section{Financial strain and birth weight}

A partial correlation was utilized to examine the relationship between financial strain and birth weight, after adjusting for gestational age at delivery. As expected, greater financial strain was negatively associated with birth weight $(r=-0.22, p=0.01)$.

\section{Relationships among psychological distress variables}

Bivariate correlations among depressive symptoms (CES-D), pregnancy-specific distress (NUPDQ), perceived stress (PSS), and general anxiety (STAI) are described in Table 2. All facets of psychological distress were positively associated with each other ( $r s=0.52$ to 0.82 , ps $<0.001)$.

\section{Mediation models}

All mediation models were adjusted for income, employment status, education level, race, smoking status, and gestational age at delivery. First, each facet of psychological distress was examined in simple mediation models. Consistent with expectations, depressive symptoms (95\% CI: $-24.65,-0.90)$ served as a mediator in the relationship between financial strain and birth weight (Table 3 and 5). In addition, pregnancy-specific distress (95\% CI: -37.31, -5.91) mediated the link between financial strain and birth weight (Table 3 and 5). In contrast, perceived stress $(-31.17,4.69)$ and general anxiety $(-25.84,5.57)$ did not serve as mediators in the link between financial strain and birth weight (Table 4 and 5). Second, given that both depressive symptoms and pregnancy-specific distress served as significant mediators, a parallel multiple mediator model was conducted. Pregnancy-specific distress $(-33.20,-0.39)$ but not depressive symptoms $(-20.70,4.18)$ remained as a significant mediator when both facets of distress were included in the same model.

\section{Conclusions}

The current study demonstrated that financial strain contributed to birth weight in a racially diverse sample of 138 pregnant women. These data extend prior research operationalizing financial stress in terms of traditional SES indicators (e.g., income) by showing that greater financial strain is positively associated with depressive symptoms, pregnancy-specific distress, perceived stress, and general anxiety as well as negatively associated with birth weight after adjustment for gestational age. This is consistent with prior data showing a positive relationship between financial strain and depressive symptoms during pregnancy and postpartum (Dailey and Humphreys 2011; Grote and Bledsoe 2007; Husain et al. 2012). In addition, financial strain was linked with birth weight via depressive symptoms and pregnancy-specific distress; further examination showed that this mediation was driven by pregnancy-specific distress.

Prior research has largely examined the direct influence of SES (e.g., employment) on adverse birth outcomes or its role as a moderator with other sociodemographic risk factors (Hoffman and Hatch 2000; Lobel et al. 2008; Paarlberg et al. 1999; Steer et al. 1992; Zimmer-Gembeck and Helfand 1996). Zhao and colleagues examined smoking during pregnancy, second-hand smoking, drinking, substance use, and gestational weight gain as potential mediators in the link between financial stress, as measured by SES indicators and 
inability to pay bills, and delivering babies of low birth weight among 2,053 African American women (2015). Results did not support these health behaviors as serving mediating roles (Zhao et al. 2015). The current study extends this literature by showing the mechanistic role of pregnancy-specific distress in the link between financial strain and birth weight. Replication of these findings will help elucidate whether this model applies to the relationship between other types of stressor exposures (e.g., discrimination) and birth weight, as posited in the literature (Dunkel Schetter and Lobel 2010; Dunkel Schetter and Tanner 2012).

Pregnancy-specific distress and depressive symptoms both served as mediators in the link between financial strain and birth weight in separate models; however, when included in the same model, only pregnancy-specific distress remained significant. This was over and beyond the effect of smoking status; a known contributor to reduced birth weight (Gissler et al. 2003; Villalbí et al. 2007). While pregnancy-specific measures demonstrate convergent validity with other types of distress, they assess a distinct construct in the context of pregnancy (Alderdice et al. 2012). In fact, prior studies show a particularly potent effect of pregnancy-specific distress on adverse birth outcomes (Dunkel Schetter and Lobel 2010; Dunkel Schetter and Tanner 2012; Lobel et al. 2008). The current study provides support for these studies by showing that pregnancy-specific distress is a primary factor linking financial strain and birth weight.

In the current study, perceived stress and general anxiety did not mediate the relationship between financial strain and birth weight. This is consistent with prior studies showing small and non-significant effects in the relationship between perceived stress and birth weight as well as general anxiety and birth weight (Dunkel Schetter and Lobel 2010; Dunkel Schetter and Tanner 2012). While these facets of distress may be associated with other types of health outcomes during pregnancy, if efforts are aimed at improving adverse birth outcomes it seems particularly important to focus attention on pregnancy-specific distress.

The current findings are of clinical relevance. Interventions targeting pregnancy-specific distress may mitigate the effects of financial strain on birth weight in pregnant women. Evidence has shown that some therapeutic interventions targeting distress, such as relaxation techniques, improve birth outcomes (e.g., Beddoe and Lee 2008). Examination of the reduction of pregnancy-specific distress as a mechanism of change in improving these outcomes would be fruitful. In addition, the unique aspects of pregnancy-specific distress should be considered in the development and evaluation of clinical screenings and interventions associated with improving birth weight outcomes. This recommendation is consistent with prior literature summarizing the predictive value of pregnancy-specific distress on preterm birth (Alderdice et al. 2012).

Birth weight was examined as a continuous outcome in the current study. Consistent with rates in the larger US population (Hamilton et al. 2013), clinically-defined low birth weight $(<2,500 \mathrm{~g})$ affected $8 \%(n=11)$ of infants in the current study which did not provide statistical power to utilize this variable dichotomously. However, continuous assessment of birth weight has been associated with both child and adult health outcomes, including cognitive functioning (Breslau et al. 1996; Matte et al. 2001; Richards et al. 2001; Sørensen 
et al. 1997). Thus, information gleaned from these analyses is applicable to the larger literature base. However, replication of these findings in a larger cohort with sufficient power to examine clinically low birth weight would be informative.

In addition, mechanistic research including biomarkers would be fruitful in describing more comprehensive models. Low SES, as defined by traditional SES indicators such as income, has been linked with heightened concentrations of serum proinflammatory markers, including interleukin-6, tumor necrosis factor-a, and C-reactive protein (Friedman and Herd 2010; Gruenewald et al. 2009; Koster et al. 2006; Loucks et al. 2010; Morozink et al. 2010; Ranjit et al. 2007). Data examining the relationship between financial strain and cytokines is lacking, despite the fact that maternal inflammatory markers have been implicated in adverse birth outcomes (Blair et al. 2015; Coussons-Read et al. 2012; Sorokin et al. 2010). Thus, data on the role of biomarkers would further elucidate the relationship between financial strain and birth weight.

This study did not examine outcomes beyond birth weight. As described earlier, financial strain has been shown to contribute to a myriad of adverse health outcomes in women, including increased oxidative stress levels, greater malnutrition risk, lower self-rated health, and recurrent coronary events (Georgiades et al. 2009; Palta et al. 2015; Samuel et al. 2012; Shippee et al. 2012). Research within the context of pregnancy and postpartum has primarily operationalized financial stress utilizing traditional SES indicators (e.g., income) and financial events (e.g., loss of employment). This study provides support for the inclusion of financial strain in studies examining clinically-relevant outcomes during pregnancy.

In sum, this study provides novel data on the role of financial strain in contributing to lower birth weight among a racially diverse sample of 138 pregnant women. These findings demonstrate that pregnancy-specific distress and depressive symptoms, but not perceived stress or general anxiety, serve as mediators in the relationship between financial strain and birth weight in pregnant women. In addition, the current data showed that only pregnancyspecific distress remained as a significant mediator when included in a multiple mediator model with depressive symptoms. Thus, future studies examining the impact of interventions reducing pregnancy-specific distress on the relationship between financial strain and birth weight are warranted. In addition, examination of whether psychological distress accounts for the relationship between other types of stressor exposures and birth weight would be informative.

\section{Acknowledgments}

We appreciate the contributions of our Clinical Research Assistants and students to data collection. We would like to thank our study participants and the staff at the OSU Clinical Research Center and Wexner Medical Center Prenatal Clinic.

\section{References}

Alderdice F, Lynn F, Lobel M. A review and psychometric evaluation of pregnancy-specific stress measures. Journal of Psychosomatic Obstetrics \& Gynecology. 2012; 33:62-77. [PubMed: 22554138] 
Beddoe AE, Lee KA. Mind-Body Interventions During Pregnancy. Journal of Obstetric, Gynecologic, \& Neonatal Nursing. 2008; 37:165-175.

Blair L, Porter K, Leblebicioglu B, Christian L. Poor sleep quality and associated inflammation predict preterm birth: Heightened risk among. African Americans Sleep. 2015; 38:1259-1267. [PubMed: 25845693]

Blumenshine P, Egerter S, Barclay CJ, Cubbin C, Braveman PA. Socioeconomic disparities in adverse birth outcomes: a systematic review. American journal of preventive medicine. 2010; 39:263-272. [PubMed: 20709259]

Breslau N, Chilcoat H, DelDotto J, Andreski P, Brown G. Low birth weight and neurocognitive status at six years of age. Biological psychiatry. 1996; 40:389-397. [PubMed: 8874840]

Christian LM, Franco A, Glaser R, Iams JD. Depressive symptoms are associated with elevated serum proinflammatory cytokines among pregnant women. Brain, Behavior, \& Immunity. 2009; 23:750754. DOI: 10.1016/j.bbi.2009.02.012

Christian LM, Franco A, Iams JD, Sheridan J, Glaser R. Depressive symptoms predict exaggerated inflammatory responses to an in vivo immune challenge among pregnant women. Brain, Behavior, \& Immunity. 2010; 24:49-53. DOI: 10.1016/j.bbi.2009.05.055

Cohen S, Kamarck T, Mermelstein R. A global measure of perceived stress. Journal of Health and Social Behavior. 1983:385-396. [PubMed: 6668417]

Conger RD, Ge X, Elder GH, Lorenz FO, Simons RL. Economic stress, coercive family process, and developmental problems of adolescents. Child development. 1994; 65:541-561. [PubMed: 8013239]

Coussons-Read ME, et al. The occurrence of preterm delivery is linked to pregnancy-specific distress and elevated inflammatory markers across gestation. Brain, Behavior, and Immunity. 2012; 26:650-659.

Dailey DE, Humphreys JC. Social Stressors Associated With Antepartum Depressive Symptoms in Low-Income African American Women Public health nursing. 2011; 28:203-212.

Dunkel Schetter, C.; Lobel, M. Pregnancy and birth: a multilevel analysis of stress and birth weight. In: Revenson, TA.; Baum, A.; Singer, J., editors. Handbook of Health Psychology. Psychology Press; New York, NY: 2010. p. 431-464.

Dunkel Schetter C, Tanner L. Anxiety, depression and stress in pregnancy: implications for mothers, children, research, and practice. Current Opinion in Psychiatry. 2012; 25:141. [PubMed: 22262028]

Friedman EM, Herd P. Income, education, and inflammation: differential associations in a national probability sample (the MIDUS study). Psychosomatic medicine. 2010; 72:290. [PubMed: 20100883]

Georgiades A, Janszky I, Blom M, László KD, Ahnve S. Financial strain predicts recurrent events among women with coronary artery disease. International Journal of Cardiology. 2009; 135:175183. [PubMed: 18619689]

Gissler M, Meriläinen J, Vuori E, Hemminki E. Register based monitoring shows decreasing socioeconomic differences in Finnish perinatal health. Journal of epidemiology and community health. 2003; 57:433-439. [PubMed: 12775790]

Grote NK, Bledsoe SE. Predicting postpartum depressive symptoms in new mothers: The role of optimism and stress frequency during pregnancy. Health \& Social Work. 2007; 32:107-118. [PubMed: 17571644]

Gruenewald TL, Cohen S, Matthews KA, Tracy R, Seeman TE. Association of socioeconomic status with inflammation markers in black and white men and women in the Coronary Artery Risk Development in Young Adults (CARDIA) study. Social science \& medicine. 2009; 69:451-459. [PubMed: 19524346]

Hamilton BE, Hoyert DL, Martin JA, Strobino DM, Guyer B. Annual summary of vital statistics: 2010-2011. Pediatrics. 2013:548-558. [PubMed: 23400611]

Hayes, AF. Introduction to mediation, moderation, and conditional process analysis: A regressionbased approach. Guilford Press; 2013. 
Hoffman S, Hatch MC. Depressive symptomatology during pregnancy: evidence for an association with decreased fetal growth in pregnancies of lower social class women. Health Psychology. 2000; 19:535. [PubMed: 11129356]

Husain N, Cruickshank K, Husain M, Khan S, Tomenson B, Rahman A. Social stress and depression during pregnancy and in the postnatal period in British Pakistani mothers: a cohort study. Journal of affective disorders. 2012; 140:268-276. [PubMed: 22608713]

Kessler RC, Turner JB, House JS. Effects of unemployment on health in a community survey: Main, modifying, and mediating effects. Journal of Social Issues. 1988; 44:69-85.

Koster A, et al. Association of inflammatory markers with socioeconomic status. The Journals of Gerontology Series A: Biological Sciences and Medical Sciences. 2006; 61:284-290.

Lobel M, Cannella DL, Graham JE, DeVincent C, Schneider J, Meyer BA. Pregnancy-specific stress, prenatal health behaviors, and birth outcomes. Health Psychology. 2008; 27:604. [PubMed: 18823187]

Loucks EB, Pilote L, Lynch JW, Richard H, Almeida ND, Benjamin EJ, Murabito JM. Life course socioeconomic position is associated with inflammatory markers: the Framingham Offspring Study. Social science \& medicine. 2010; 71:187-195. [PubMed: 20430502]

Matte TD, Bresnahan M, Begg MD, Susser E. Influence of variation in birth weight within normal range and within sibships on IQ at age 7 years cohort study. Bmj. 2001; 323:310-314. [PubMed: 11498487]

Matthews KA, Gallo LC. Psychological perspectives on pathways linking socioeconomic status and physical health. Annual review of psychology. 2011; 62:501.

Mattison DR, Damus K, Fiore E, Petrini J, Alter C. Preterm delivery: a public health perspective. Paediatric and Perinatal Epidemiology. 2001; 15:7-16. [PubMed: 11520396]

Meades R, Ayers S. Anxiety measures validated in perinatal populations: a systematic review. Journal of affective disorders. 2011; 133:1-15. [PubMed: 21078523]

Morozink JA, Friedman EM, Coe CL, Ryff CD. Socioeconomic and psychosocial predictors of interleukin-6 in the MIDUS national sample. Health Psychology. 2010; 29:626. [PubMed: 20954777]

Paarlberg KM, Vingerhoets J, Passchier J, Dekker GA, Heinen AG, Geijn HP. Psychosocial predictors of low birthweight: a prospective study. BJOG: An International Journal of Obstetrics \& Gynaecology. 1999; 106:834-841.

Palta P, Szanton SL, Semba RD, Thorpe RJ, Varadhan R, Fried LP. Financial strain is associated with increased oxidative stress levels: The Women's Health and Aging Studies. Geriatric Nursing. 2015; 36:S33-S37. [PubMed: 25784083]

Preacher KJ, Hayes AF. Asymptotic and resampling strategies for assessing and comparing indirect effects in multiple mediator models. Behavior research methods. 2008; 40:879-891. [PubMed: 18697684]

Price RH, Choi JN, Vinokur AD. Links in the chain of adversity following job loss: how financial strain and loss of personal control lead to depression, impaired functioning, and poor health. Journal of Occupational Health Psychology. 2002; 7:302. [PubMed: 12396064]

Radloff LS. The CES-D Scale: A Self-Report Depression Scale for Research in the General Population. Applied Psychological Measurement. 1977; 1:385-401. DOI: 10.1177/014662167700100306

Ranjit N, Diez-Roux AV, Shea S, Cushman M, Ni H, Seeman T. Socioeconomic position, race/ ethnicity, and inflammation in the multi-ethnic study of atherosclerosis. Circulation. 2007; 116:2383-2390. [PubMed: 18025402]

Richards M, Hardy R, Kuh D, Wadsworth ME. Birth weight and cognitive function in the British 1946 birth cohort: longitudinal population based study. Bmj. 2001; 322:199-203. [PubMed: 11159613]

Samuel LJ, Szanton SL, Weiss CO, Thorpe RJ, Semba RD, Fried LP. Financial strain is associated with malnutrition risk in community-dwelling older women. Epidemiology Research International. $2012 ; 2012$

Shippee TP, Wilkinson LR, Ferraro KF. Accumulated financial strain and women's health over three decades. The Journals of Gerontology Series B: Psychological Sciences and Social Sciences. 2012; 67:585-594. 
Sørensen HT, Sabroe S, Olsen J, Rothman KJ, Gillman MW, Fischer P. Birth weight and cognitive function in young adult life: historical cohort study. Bmj. 1997; 315:401-403. [PubMed: 9277604]

Sorokin Y, et al. Maternal serum interleukin-6, C-reactive protein, and matrix metalloproteinase-9 concentrations as risk factors for preterm birth $<32$ weeks and adverse neonatal outcomes. American Journal of Perinatology. 2010; 27:631. [PubMed: 20195952]

Steer RA, Scholl TO, Hediger ML, Fischer RL. Self-reported depression and negative pregnancy outcomes. Journal of clinical epidemiology. 1992; 45:1093-1099. [PubMed: 1474405]

Villalbí JR, Salvador J, Cano-Serral G, Rodríguez-Sanz MC, Borrell C. Maternal smoking, social class and outcomes of pregnancy. Paediatric and perinatal epidemiology. 2007; 21:441-447. [PubMed: 17697074]

Vinokur A, Caplan RD. Attitudes and social support: Determinants of job-seeking behavior and wellbeing among the unemployed. Journal of Applied Social Psychology. 1987; 17:1007-1024.

Vinokur AD, Price RH, Caplan RD. Hard times and hurtful partners: how financial strain affects depression and relationship satisfaction of unemployed persons and their spouses. Journal of Personality and Social Psychology. 1996; 71:166. [PubMed: 8708998]

Wright RJ, et al. Prenatal maternal stress and cord blood innate and adaptive cytokine responses in an inner-city cohort. American journal of respiratory and critical care medicine. 2010; 182:25-33. [PubMed: 20194818]

Yali AM, Lobel M. Coping and distress in pregnancy: An investigation of medically high risk women. Journal of Psychosomatic Obstetrics \& Gynecology. 1999; 20:39-52. [PubMed: 10212886]

Zambrana RE, Dunkel-Schetter C, Collins NL, Scrimshaw SC. Mediators of ethnic-associated differences in infant birth weight. Journal of Urban Health. 1999; 76:102-116. [PubMed: 10091194]

Zhao Y, Kershaw T, Ettinger AS, Higgins C, Lu MC, Chao SM. Association between life event stressors and low birth weight in African American and White populations: findings from the 2007 and 2010. Los Angeles Mommy and Baby (LAMB) Surveys Maternal and child health journal. 2015:1-11.

Zimmer-Gembeck MJ, Helfand M. Low birthweight in a public prenatal care program: behavioral and psychosocial risk factors and psychosocial intervention. Social Science \& Medicine. 1996; 43:187-197. [PubMed: 8844923] 


\section{Table 1}

Demographic characteristics

\begin{tabular}{|c|c|}
\hline & $(n=138)$ \\
\hline Weeks Gestation at Visit [Mean (SD)] & $18.4(7.2)$ \\
\hline Age [Mean (SD)] & $29.3(4.9)$ \\
\hline \multicolumn{2}{|l|}{$\operatorname{Race}[n(\%)]$} \\
\hline White & $84(60.9)$ \\
\hline Black & $42(30.4)$ \\
\hline Asian & $2(1.4)$ \\
\hline Multiracial & $10(7.2)$ \\
\hline \multicolumn{2}{|l|}{ Marital Status [ $n(\%)]$} \\
\hline Married & $84(61.3)$ \\
\hline In a relationship & $33(24.1)$ \\
\hline Single & $20(14.6)$ \\
\hline \multicolumn{2}{|l|}{ Education $[n(\%)]$} \\
\hline High School Graduate or Less & $22(15.9)$ \\
\hline Some College & $34(24.6)$ \\
\hline College Degree & $38(27.5)$ \\
\hline Graduate School & $44(31.9)$ \\
\hline \multicolumn{2}{|l|}{ Income $[n(\%)]$} \\
\hline$<\$ 15,000$ & $34(24.6)$ \\
\hline$\$ 15,000-\$ 29,999$ & $18(13.0)$ \\
\hline$\$ 30,000-\$ 49,999$ & $17(12.3)$ \\
\hline$\$ 50,000-\$ 74,999$ & $19(13.8)$ \\
\hline$\$ 75,000-\$ 99,999$ & $23(16.7)$ \\
\hline$>\$ 100,000$ & $27(19.6)$ \\
\hline \multicolumn{2}{|l|}{ Employment Status $[n(\%)]$} \\
\hline Employed & $93(67.4)$ \\
\hline Unemployed & $45(32.6)$ \\
\hline \multicolumn{2}{|l|}{ Parity (\# of prev. births) [ $n(\%)]$} \\
\hline 0 & $50(36.2)$ \\
\hline 1 & $49(35.5)$ \\
\hline 2 or more & $39(28.3)$ \\
\hline \multicolumn{2}{|l|}{ Smoking Status $[n(\%)]$} \\
\hline No current use & $120(87.0)$ \\
\hline Current use & $18(13.0)$ \\
\hline Birth Weight (g) [Mean (SD)] & $3,281(546.8)$ \\
\hline Low Birth Weight $(<2500 \mathrm{~g})[n(\%)]$ & $11(8.0)$ \\
\hline
\end{tabular}




\section{Table 2}

Correlations among psychological distress variables

\begin{tabular}{|c|c|c|c|c|}
\hline & Depressive Symptoms & Pregnancy- Specific Distress & Perceived Stress & General Anxiety \\
\hline Depressive Symptoms & -- & & & \\
\hline Pregnancy-Specific Distress & $0.54^{* * *}$ & -- & & \\
\hline Perceived Stress & $0.75^{\text {**** }}$ & $0.52^{* * *}$ & -- & \\
\hline General Anxiety & $0.75^{\text {**** }}$ & $0.57^{* * * *}$ & $0.82^{* * *}$ & -- \\
\hline
\end{tabular}




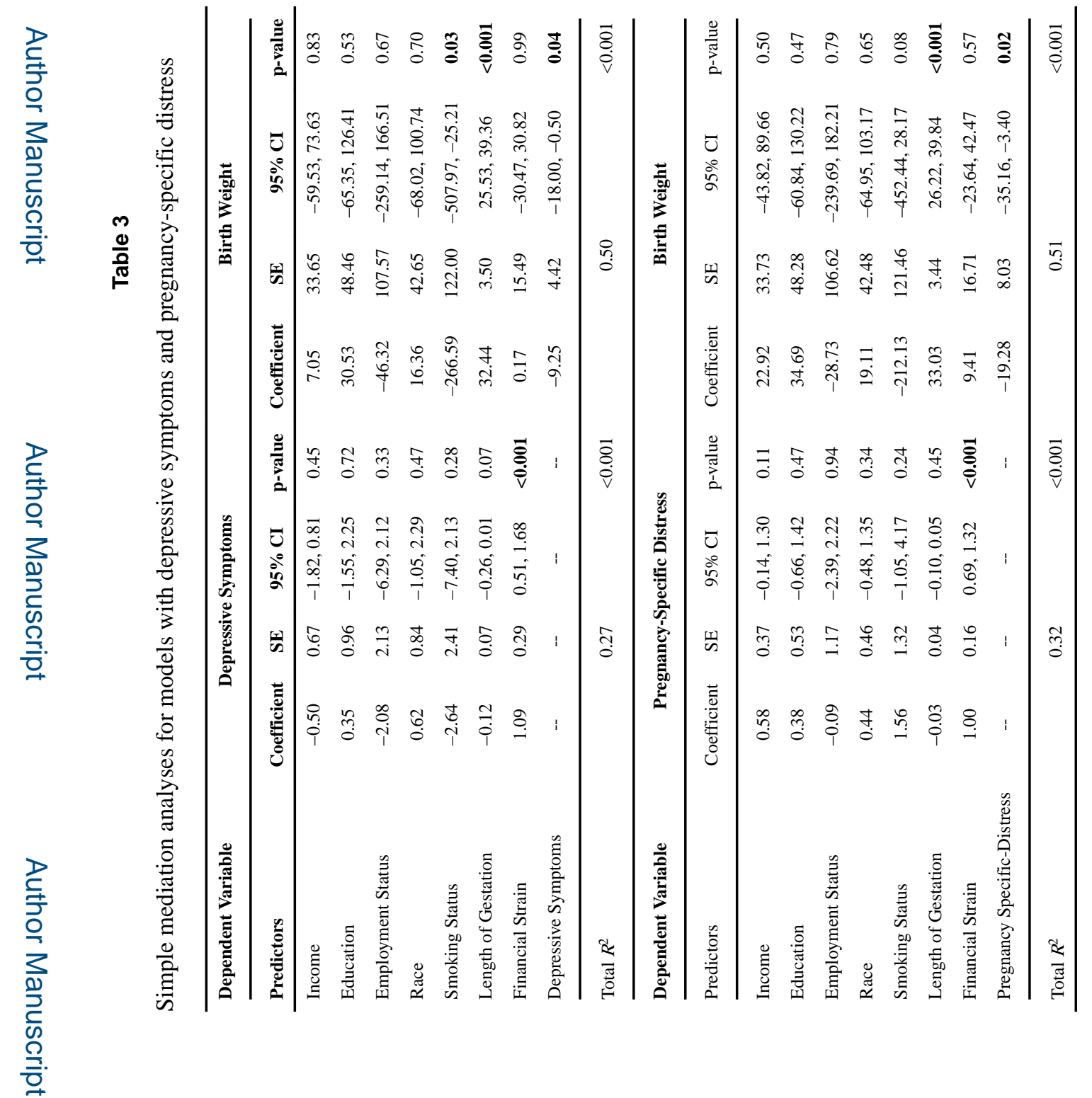

Arch Womens Ment Health. Author manuscript; available in PMC 2018 February 01. 
Table 5

Simple mediation models

\begin{tabular}{lc}
\hline Mediation Models & 95\% CI estimates \\
\hline Financial Strain $\rightarrow$ Depressive Symptoms $\rightarrow$ Birth Weight & $(-24.65,-0.90)^{* a}$ \\
Financial Strain $\rightarrow$ Pregnancy Specific-Distress $\rightarrow$ Birth Weight & $(-37.31,-5.91)^{* a}$ \\
Financial Strain $\rightarrow$ Perceived Stress $\rightarrow$ Birth Weight & $(-31.17,4.69)$ \\
Financial Strain $\rightarrow$ General Anxiety $\rightarrow$ Birth Weight & $(-25.84,5.57)$ \\
\hline Note. & \\
* Significant effect. &
\end{tabular}

Pregnancy-specific distress (95\% CI: $-33.20,-0.39)$, but not depressive symptoms (95\% CI: -20.70, 4.18), remained as a significant mediator when both facets of distress were included in the same model. 